\title{
Interferência de Plantas Daninhas sobre a Produtividade da MANDIOCA (Manihot esculenta) ${ }^{1}$
}

\author{
Weed Interference in Cassava (Manihot esculenta) Yield
}

\author{
ALBUQUERQUE, J.A.A. ${ }^{2}$, SEDIYAMA, T. ${ }^{3}$, SILVA, A.A. ${ }^{3}$, CARNEIRO, J.E.S. ${ }^{3}$, CECON, P.R. ${ }^{4}$ e \\ ALVES, J.M.A. ${ }^{2}$
}

\begin{abstract}
RESUMO - O manejo inadequado das plantas daninhas é uma das principais causas da baixa produtividade da cultura da mandioca no Brasil. Objetivou-se com este trabalho identificar as espécies de plantas daninhas infestantes da cultura da mandioca e o grau de interferência que estas exercem sobre o cultivo, em função do período de convivência com a cultura. Dois experimentos foram realizados em áreas adjacentes, no municipio de ViçosaMG, utilizando-se o cultivar Cacauzinha, do grupo das mandiocas mansas. O delineamento experimental adotado foi em blocos casualizados, com sete tratamentos e quatro repetições. Os tratamentos do primeiro experimento foram compostos por periodos iniciais de convivência da cultura com as plantas daninhas: 25, 50, 75, 100 e 125 dias após o plantio (DAP); no segundo experimento, as plantas de mandioca, inicialmente, permaneceram livres das plantas daninhas pelos mesmos periodos. Em ambos os experimentos adotou-se o espaçamento de $1,0 \times 0,5 \mathrm{~m}$, sendo a área útil da parcela constituída pelas duas linhas centrais, deixando-se $1,0 \mathrm{~m}$ em cada extremidade como bordaduras frontais, totalizando $8,0 \mathrm{~m}^{2}$. As plantas daninhas foram avaliadas aos 25, 50, 75, 100, 125, 150, 175, 200, 225, 250, 275, 300, 325 e 350 DAP. As características produtividade de raizes, peso da parte aérea, indice de colheita, teor de amido e matéria seca das raízes foram avaliadas aos 12 meses após o plantio. As espécies de plantas daninhas que predominaram na área experimental foram: Bidens pilosa, Raphanus raphanistrum, Cyperus rotundus e Commelina benghalensis, com a primeira delas predominando em quase todas as épocas de coletas. Os períodos de convivência com as plantas daninhas não interferiram nos índices de colheita, teor de amido e matéria seca das raizes. Todavia, considerando a produtividade de raizes, o final do período anterior à interferência foi próximo dos 25 dias, e o período crítico de prevenção da interferência situou-se entre 25 e 75 DAP. Cultivos realizados após 75 DAP não afetaram as características da cultura da mandioca avaliadas.
\end{abstract}

Palavras-chave: capinas, competição, período de convivência.

\begin{abstract}
Inadequate handling of weeds is one of the main causes of cassava low yield in Brazil. The objective of this work was to identify the weed species interfering in cassava crop and the degree of this interference, in function of then coexistence period. Two experiments were carried out in adjacent areas in Viçosa-MG, Brazil, using the "cacauzinha" cultivar of the cassava group. A randomized block design was adopted, with seven treatments and four replications. The treatments in the first experiment were composed by the initial crop periods and weed coexistence 25, 50, 75, 100 and 125 days after planting (DAP). In the second experiment, the cassava plants initially remained weed-free for the same periods. For both experiments, $1.0 \times 0.5 \mathrm{~m}$ spacing was adopted, being the useful portion area constituted by the two central lines, with $1.0 \mathrm{~m}$ being
\end{abstract}

1 Recebido para publicação em 8.5.2007 e na forma revisada em 20.3.2008.

Parte da Tese de Doutorado do primeiro autor apresentada à Universidade Federal de Viçosa-UFV. Projeto financiado pela CAPES/PICDT.

2 Professores, D.Sc., do Dep. de Fitotecnia da UFRR, Boa Vista-Roraima, <anchietaufrr@gmail.com.br>; ${ }^{3}$ Professores, D.Sc., do Dep. de Fitotecnia da UFV, Bolsistas do CNPq; ${ }^{4}$ Prof., D. Sc., do Dep. de Informática da UFV. Bolsista do CNPq. 
left in each extremity as front borders, totaling $8.0 \mathrm{~m}^{2}$. The weeds were analyzed at 25, 50, 75, $100,125,150,175,200,225,250,275,300,325$ and 350 DAP. The characteristics root yield, aerial part weight, crop index, starch content and root dry matter were evaluated at twelve months after planting. The prevailing weed species in the experimental area were: Bidens pilosa, Raphanus raphanistrum, Cyperus rotundus and Commelina benghalensis, with Bidens pilosa prevailing in almost all collection times. The coexistence periods with the weeds did not interfere in the crop indexes, starch content and root dry matter. However, taking into account root yield, the end of the period before interference was close to 25 days and the interference prevention critical period was between 25 and 75 DAP. Crops sown after 75 DAP did not affect the analyzed cassava crop characteristics.

Keywords: hoeing, competition, coexistence period.

\section{INTRODUÇÃO}

A mandioca (Manihot esculenta) constitui uma das principais fontes econômicas de carboidratos nos trópicos, desempenhando papel importante na alimentação humana e animal e na indústria de processamento de farinha e fécula. A grande contribuição da mandioca reside, principalmente, na alimentação das populações de baixa renda, em que mais de 700 milhões de pessoas recebem de 200 a 1.000 calorias diárias fornecidas por essa cultura. O Brasil contribui com aproximadamente $15 \%$ da produção mundial, destacando-se como o segundo maior produtor mundial, atrás apenas da Nigéria (FAO, 2006). Acredita-se que a Amazônia seja a região do mundo onde a mandioca apresenta o maior número de formas de aproveitamento ou utilização. Esses aspectos têm levado alguns pesquisadores a considerarem-na como sendo o local de origem e domesticação dessa cultura (Albuquerque \& Cardoso, 1983).

Apesar de apresentar alto potencial produtivo, alcançando em algumas regiões produtividades superiores a $80 \mathrm{t} \mathrm{ha}^{-1}$, a produtividade nacional é baixa, não tem evoluído e está em torno de 13,80 $\mathrm{tha}^{-1}$ (IBGE, 2006). Em trabalho realizado pelo IITA (2005), no Quênia, onde foram avaliados 400 cultivares de mandioca para produção de raízes tuberosas, foram observados cultivares altamente produtivos. Quatro deles produziram aproximadamente $100 \mathrm{t} \mathrm{ha}^{-1}$, enquanto novos materiais que estão sendo selecionados chegaram a produzir $150 \mathrm{t} \mathrm{ha}^{-1}$, sugerindo, portanto, que a capacidade de produção da espécie ainda não é conhecida. Um dos fatores que têm contribuído para essa baixa produtividade da cultura em nivel nacional é o manejo inadequado das plantas daninhas. Normalmente os produtores de mandioca acreditam que, por ser essa cultura rústica, não precisam se preocupar com o controle das plantas daninhas, as quais estão sempre presentes nos mandiocais.

Considerando o custo de produção da mandioca, acredita-se que uma parcela significativa se deva ao controle das plantas daninhas; contudo, esse valor é dependente de vários fatores, como a espécie e a densidade populacional da daninha infestante, o sistema de plantio e o método de controle aplicado. Entretanto, sabe-se que a cultura da mandioca é altamente suscetível à competição com as plantas daninhas. Perdas em produção de raízes em decorrência da competição com as plantas daninhas durante o cultivo da mandioca podem chegar a 90\%, em função do tempo de convivência e da densidade das espécies infestantes (Carvalho, 2000; Mattos \& Cardoso, 2005). Dentre os fatores bióticos, as plantas daninhas são consideradas um dos principais componentes do agroecossistema da mandioca que interferem no desenvolvimento e na produtividade dessa cultura. Todavia, o grau de interferência das plantas daninhas nas culturas depende de fatores ligados à própria cultura, à comunidade infestante, ao ambiente e ao período em que elas convivem (Silva et al., 2007). Nesse processo, um dos fatores mais facilmente controláveis, na prática, é a extensão do período de convivência entre culturas e plantas daninhas (Pitelli, 1985). De acordo com Carvalho (2000), o grau dessa competição depende das espécies, 
da densidade populacional e, principalmente, do período em que permanecem vegetando juntas.

A cultura da mandioca possui crescimento inicial lento, deixando o solo descoberto, facilitando, dessa forma, o desenvolvimento de plantas daninhas, que competem com a cultura pelos elementos: água, luz, nutrientes, gás carbônico e espaço, ocasionando maiores perdas do que aquelas provocadas pelas pragas e doenças (Azevêdo et al., 2006). É importante e necessária a identificação das espécies mais freqüentes, pois cada uma - de acordo com seu potencial de estabelecer-se na área e sua agressividade - pode interferir de forma diferenciada na cultura da mandioca. Segundo premissas do Manejo Integrado de Plantas Daninhas - MIPD, além do conhecimento do dano, ou interferência, proporcionado pelas plantas daninhas, torna-se fundamental a identificação destas para que haja recomendação adequada de herbicidas ou outras formas de controle, bem como para fazer o monitoramento da presença de certas espécies de plantas daninhas nas regiões onde se cultiva a mandioca (Alcântara et al., 1982).

Na cultura da mandioca, além do uso de herbicidas, a prática da capina manual é também bastante utilizada; assim, o conhecimento do período crítico de interferência das plantas daninhas é uma ferramenta importante para se estabelecer quando iniciar e o número de capinas a serem realizadas.

Objetivou-se neste trabalho identificar as principais espécies de plantas daninhas infestantes durante o cultivo da mandioca e o grau de interferência delas na cultura, visando iniciar e terminar as intervenções na lavoura para controle das plantas daninhas.

\section{MATERIAL E MÉTODOS}

Foram realizados dois experimentos no município de Viçosa-MG, em áreas adjacentes, no Campo Experimental Professor Diogo Alves de Mello, pertencente ao Departamento de Fitotecnia da Universidade Federal de Viçosa, em solo classificado como Argissolo VermelhoAmarelo, cujas análises granulométrica e química são apresentadas na Tabela 1. Os dados referentes a precipitação pluvial $(\mathrm{mm})$, umidade relativa do ar (\%) e temperatura média $\left({ }^{\circ} \mathrm{C}\right)$, no período em que foi conduzido o trabalho, são apresentados na Figura 1.

O delineamento experimental adotado foi o de blocos casualizados, com sete tratamentos e quatro repetições. Os tratamentos do primeiro experimento foram compostos por diferentes períodos de convivência das plantas daninhas com a cultura da mandioca, conforme especificado na Tabela 2.

O solo foi preparado com aração, gradagem e sulcamento. A área experimental foi adubada de acordo com análise do solo e conforme a recomendação para a cultura da mandioca, 5aㅗ Aproximação (CFSEMG, 1999). O plantio foi realizado dia 22 de dezembro de 2003, utilizando-se ramas do cultivar denominado $\mathrm{Ca}-$ cauzinha, do grupo das mandiocas mansas. A colheita foi realizada em 22 de dezembro de 2004.

Para o plantio das manivas, foram adotados espaçamentos de $1,0 \times 0,5 \mathrm{~m}$; cada parcela foi

Tabela 1 - Análise granulométrica e química da camada arável $(0-20 \mathrm{~cm})$ do solo Argissolo Vermelho-Amarelo utilizado no experimento ${ }^{1 /}$

\begin{tabular}{|c|c|c|c|c|c|c|c|c|c|c|}
\hline \multicolumn{11}{|c|}{ Análise granulométrica $\left(\mathrm{dag} \mathrm{kg}^{-1}\right)$} \\
\hline \multicolumn{2}{|c|}{ Argila } & \multicolumn{2}{|r|}{ Silte } & \multicolumn{2}{|c|}{ Areia fina } & \multicolumn{2}{|c|}{ Areia grossa } & \multicolumn{3}{|c|}{ Classificação textural } \\
\hline \multicolumn{2}{|c|}{34} & \multicolumn{2}{|r|}{12} & \multicolumn{2}{|c|}{18} & \multicolumn{2}{|c|}{36} & \multicolumn{3}{|c|}{ Franco-Argilo-Arenoso } \\
\hline \multicolumn{11}{|c|}{ Análise química } \\
\hline $\mathrm{pH}$ & $\mathrm{P}^{\underline{2} /}$ & $\mathrm{K}^{+2} /$ & $\mathrm{H}+\mathrm{Al}^{\underline{3} /}$ & $\mathrm{Al}^{3+} \underline{4}$ & $\mathrm{Ca}^{2+} 4 /$ & $\mathrm{Mg}^{2+} \underline{4}$ & $\mathrm{CTC}_{\text {total }}$ & $\mathrm{V}$ & $\mathrm{m}$ & $\mathrm{MO}$ \\
\hline $\mathrm{H}_{2} \mathrm{O}$ & \multicolumn{2}{|c|}{$---\mathrm{mg} \mathrm{dm}^{-3}---$} & \multicolumn{5}{|c|}{---------------------- $\mathrm{cmol}_{\mathrm{c}} \mathrm{dm}^{-3}$} & \multicolumn{2}{|c|}{-------- $\%$-------- } & dag $\mathrm{kg}^{-1}$ \\
\hline 5,5 & 7,4 & 76 & 2,7 & 0,0 & 2,8 & 0,8 & 3,61 & 56 & 0 & 3,68 \\
\hline
\end{tabular}

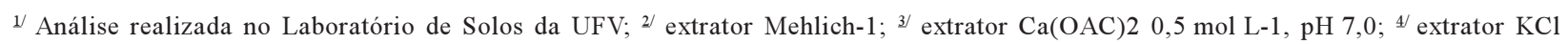
1 mol L-1. 


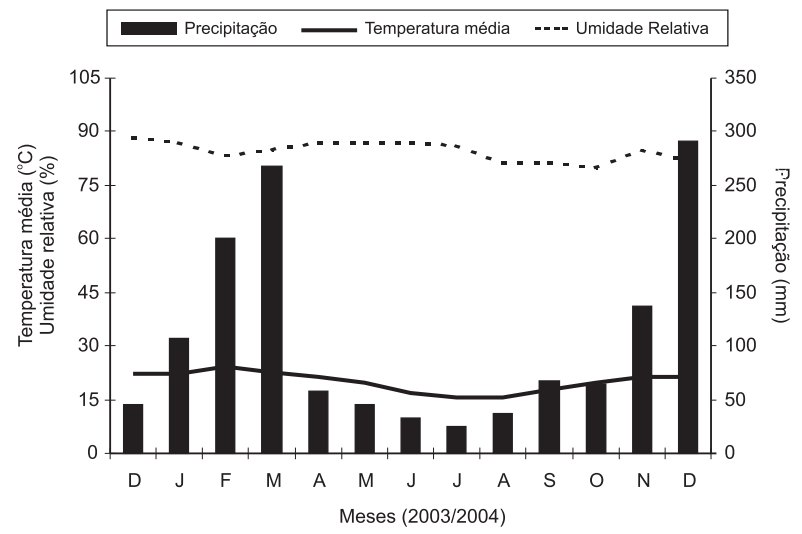

Figura 1 - Precipitação pluvial (mm), umidade relativa do ar $(\%)$ e temperatura média $\left({ }^{\circ} \mathrm{C}\right)$ no período entre dezembro de 2003 e dezembro de 2004. Dados obtidos da estação meteorológica pertencente ao Departamento de Engenharia Agrícola da UFV.

Tabela 2 - Descrição dos tratamentos avaliados no experimento 1. Viçosa-MG, 2006

\begin{tabular}{|l|l|}
\hline \multicolumn{1}{|c|}{ Tratamento } & \multicolumn{1}{c|}{ Descrição } \\
\hline Testemunha 1 ${ }^{1 /}$ & Cultura mantida sempre no limpo \\
\hline CPD $^{\underline{3} /} 25$ DAP $^{4 /}$ & $\begin{array}{l}\text { Convivência com plantas daninhas } \\
25 \text { dias após o plantio }\end{array}$ \\
\hline CPD 50 DAP & $\begin{array}{l}\text { Convivência com plantas daninhas } \\
50 \text { dias após o plantio }\end{array}$ \\
\hline CPD 75 DAP & $\begin{array}{l}\text { Convivência com plantas daninhas } \\
75 \text { dias após o plantio }\end{array}$ \\
\hline CPD 100 DAP & $\begin{array}{l}\text { Convivência com plantas daninhas } \\
100 \text { dias após o plantio }\end{array}$ \\
\hline CPD 125 DAP & $\begin{array}{l}\text { Convivência com plantas daninhas } \\
125 \text { dias após o plantio }\end{array}$ \\
\hline Testemunha 2 2 - & $\begin{array}{l}\text { Convivência com plantas daninhas } \\
\text { até o final do ciclo }\end{array}$ \\
\hline
\end{tabular}

1/ Cultivo livre de plantas daninhas durante todo o ciclo; 2/ cultivo com plantas daninhas durante todo o ciclo; ${ }^{3}$ convivência com plantas daninhas; ${ }^{4 /}$ dias após o plantio

constituída por quatro linhas de $6 \mathrm{~m}$ de comprimento e $4 \mathrm{~m}$ de largura, totalizando $24 \mathrm{~m}^{2}$. A área útil da parcela foi representada por duas linhas centrais, deixando-se 1,0 m em cada extremidade como bordaduras frontais, com uma área útil de $8,0 \mathrm{~m}^{2}$. As avaliações das plantas daninhas foram realizadas aos $25,50,75$, $100,125,150,175,200,255,250,275,300$, 325 e 350 DAP da cultura da mandioca. Por ocasião dessas avaliações, fez-se a coleta das plantas daninhas por meio de amostragens. Para isso, foi utilizado um quadrado de madeira de $0,5 \times 0,5 \mathrm{~m}$ de dimensão, lançado aleatoriamente na área útil em cada unidade experimental. As plantas daninhas situadas nas áreas amostradas foram seccionadas rente ao solo e, em seguida, levadas ao laboratório, onde foram feitas as identificações, a contagem e a pesagem da massa fresca das espécies.

No segundo experimento, os tratamentos foram compostos por diferentes períodos de capina, mantendo-se a cultura livre da interferência das plantas daninhas após o plantio, conforme especificado na Tabela 3. As etapas de amostragem, identificação e pesagem das plantas daninhas foram semelhantes às especificadas no experimento 1 .

Tabela 3 - Descrição dos tratamentos avaliados no experimento 2. Viçosa-MG, 2006

\begin{tabular}{|c|c|}
\hline Tratamento & Descrição \\
\hline Testemunha $1^{1 /}$ & Cultura mantida sempre no limpo \\
\hline $\mathrm{LPD}^{3 / /} 25 \mathrm{DAP}^{4 /}$ & $\begin{array}{l}\text { Livre de plantas daninhas } 25 \text { dias } \\
\text { após o plantio }\end{array}$ \\
\hline LPD 50 DAP & $\begin{array}{l}\text { Livre de plantas daninhas } 50 \text { dias } \\
\text { após o plantio }\end{array}$ \\
\hline LPD 75 DAP & $\begin{array}{l}\text { Livre de plantas daninhas } 75 \text { dias } \\
\text { após o plantio }\end{array}$ \\
\hline LPD 100 DAP & $\begin{array}{l}\text { Livre de plantas daninhas } 100 \text { dias } \\
\text { após o plantio }\end{array}$ \\
\hline LPD 125 DAP & $\begin{array}{l}\text { Livre de plantas daninhas } 125 \text { dias } \\
\text { após o plantio }\end{array}$ \\
\hline 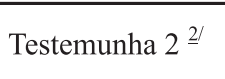 & $\begin{array}{l}\text { Cultura mantida sempre com plantas } \\
\text { daninhas }\end{array}$ \\
\hline
\end{tabular}

1/ e 2/ Cultivo livre e com plantas daninhas durante todo o ciclo, respectivamente; ${ }^{3 /}$ livre de plantas daninhas; ${ }^{4 /}$ dias após o plantio.

Em ambos os experimentos, foram avaliadas aos 12 meses após o plantio as seguintes caracteristicas: produtividade de raizes $\left(\mathrm{kg} \mathrm{ha}^{-1}\right)$, peso da parte aérea $\left(\mathrm{kg} \mathrm{ha}^{-1}\right)$, índice de colheita (\%), teor de amido (\%) e matéria seca das raízes. Para a produtividade de raízes, foram coletadas as raízes da área útil; em seguida, elas foram limpas e pesadas em balança de precisão de $0,1 \mathrm{~g}$. Separou-se a parte aérea das plantas (folhas e caule), seccionando-se a uma altura aproximada de $15 \mathrm{~cm}$ do solo; a seguir foi quantificada a sua massa verde. A característica índice de colheita foi avaliada utilizando-se a fórmula: $\mathrm{IC}=($ peso raízes $\mathrm{x} 100) \div$ 
(peso raízes + peso parte aérea). As características teor de amido e matéria seca das raízes foram determinadas pelo método da balança hidrostática (Grossmann \& Freitas, 1950), admitindo-se zero para as medidas inferiores a três quilogramas de raizes.

A análise estatística dos dados foi realizada utilizando-se o programa SAEG (Ribeiro Jr., 2004). Os dados obtidos referentes a produtividade de raízes, peso da parte aérea, índice de colheita, teor de amido e matéria seca das raízes foram submetidos à análise de variância ( $p>0,05)$. Na comparação das médias foi empregado o teste de Tukey a $5 \%$ de probabilidade. As características de massa fresca total e espécies daninhas foram avaliadas por meio de análise descritiva.

\section{RESULTADOS E DISCUSSÃO}

A composição da comunidade infestante de plantas daninhas na área experimental foi heterogênea, apresentando 37 espécies, distribuídas em 30 gêneros e 14 famílias. As famílias com maior ocorrência foram Compositae, Gramineae e Amaranthaceae, com nove, sete e quatro espécies, respectivamente (Tabela 4). As espécies que predominaram foram: Bidens pilosa $(14,46 \%)$, Raphanus raphanistrum (8,70\%), Cyperus rotundus (8,44\%), Commelina benghalensis $(7,56 \%)$, Ageratum conyzoides (7,01\%), Ipomoea purpurea (6,31\%), Brachiaria plantaginea $(4,81 \%)$, Sonchus oleraceus $(4,79 \%)$, e Digitaria horizontalis (2,15\%) (Figura 2).

No total das 37 espécies de plantas daninhas encontradas na área experimental, nem todas estiveram presentes em todos os meses

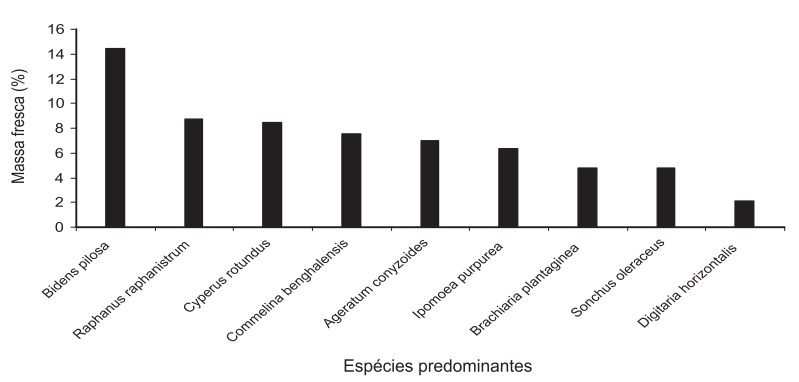

Figura 2 - Média da produção de massa fresca (\% em relação à massa total) das espécies de plantas daninhas que predominaram na área experimental. Viçosa-MG, 2006. do ano, possivelmente devido ao fato de as sementes das plantas infestantes encontraremse no solo em estado de dormência, aguardando as melhores condições de temperatura e umidade para germinarem. Segundo Carvalho (2000), levantamentos realizados em Minas Gerais e na Bahia identificaram mais de 200 espécies, representando mais de 100 gêneros pertencentes a mais de 40 familias, entre Liliopsidas e Magnoliopsidas. Esse autor afirma ainda que as de maior ocorrência foram Compositae, Gramineae, Leguminosae, Rubiaceae, Malvaceae, Euphorbiaceae, Convolvulaceae, Portulaceae, Amaranthaceae, Commelinaceae, Cyperaceae e Molluginaceae. Algumas das espécies de plantas daninhas que ocorrem em mandiocais podem ser consideradas como problemas local ou regional, pois cada região tem sua peculiaridade quanto às plantas daninhas predominantes, ainda que haja muitas delas em comum nas diversas regiões produtoras de mandioca no Brasil.

Em cada época de coleta, algumas espécies se destacaram, em razão de vários fatores, dentre os quais: características da espécie, clima, banco de sementes, desenvolvimento da cultura da mandioca e as capinas programadas. Nos meses de elevada precipitação pluvial e alta temperatura, observou-se maior infestação de plantas daninhas (Figuras 1 e 3). As monocotiledôneas apresentaram boa produção de massa fresca nos períodos de coleta dos 25 aos 125 dias (Figura 3). Viegas (1976) verificou que a tiririca é um sério problema para os mandiocais brasileiros nos primeiros meses após o plantio; contudo, com manejo adequado é possivel dominá-la até mesmo em culturas anuais (Jakelaitis et al., 2003). A mandioca consegue conviver com baixa infestação de tiririca, sem redução significativa no crescimento e acúmulo de matéria seca total (Paixão et al., 1995).

Entre as espécies de folhas largas, Bidens pilosa predominou em quase todas as épocas de coleta (Figuras 3 e 4). Esse fato pode ser explicado porque as sementes oriundas de uma mesma planta de Bidens pilosa podem ter diferentes graus de dormência, o que torna a sua germinação escalonada no tempo. Nas épocas preestabelecidas de coleta, foi observado que aos 25 dias houve predominância de Cyperus rotundus (106 $\left.\mathrm{g} \mathrm{m}^{-2}\right)$; aos 50 dias, de 
Tabela 4 - Nomes comuns, científicos e famílias botânicas das 37 espécies coletadas durante a condução dos experimentos. Viçosa$\mathrm{MG}, 2006$

\begin{tabular}{|c|c|c|}
\hline Nome comum & Nome científico & Família \\
\hline Capim-colchão & Digitaria horizontalis & Gramineae \\
\hline Capim-marmelada & Brachiaria plantaginea & Gramineae \\
\hline Grama-seda & Cynodon dactylon & Gramineae \\
\hline Capim-rabo-de-raposa & Setaria geniculata & Gramineae \\
\hline Capim-pé-de-galinha & Eleusine indica & Gramineae \\
\hline Capim-amargoso & Digitaria insularis & Gramineae \\
\hline Capim-carrapicho & Cenchrus echinatus & Gramineae \\
\hline Picão-preto & Bidens pilosa & Compositae \\
\hline Mentrasto & Ageratum conyzoides & Compositae \\
\hline Falsa-serralha & Emilia sonchifolia & Compositae \\
\hline Serralha & Sonchus oleraceus & Compositae \\
\hline Botão-de-ouro & Galinsoga parviflora & Compositae \\
\hline Botão-de-ouro & Galinsoga quadriradiata & Compositae \\
\hline Cicuta (coentro-do-mato) & Parthenium hysterophorus & Compositae \\
\hline Carrapicho-de-carneiro & Acanthospermum hispidum & Compositae \\
\hline Losna-do-campo & Ambrosia elatior & Compositae \\
\hline Apaga-fogo & Alternanthera tenella & Amaranthaceae \\
\hline Caruru-branco & Amaranthus hybridus & Amaranthaceae \\
\hline Caruru-gigante & Amaranthus retroflexus & Amaranthaceae \\
\hline Caruru-rasteiro & Amaranthus deflexus & Amaranthaceae \\
\hline Maria-pretinha & Solanum americanum & Solanaceae \\
\hline Joá-de-capote & Nicandra physaloides & Solanaceae \\
\hline Bucho-de-rã & Physalis angulata & Solanaceae \\
\hline Corda-de-viola & Ipomoea purpurea & Convolvulaceae \\
\hline Corda-de-viola (gigante) & Ipomoea grandifolia & Convolvulaceae \\
\hline Tiririca & Cyperus rotundus & Cyperaceae \\
\hline Tiriricão & Cyperus esculentus & Cyperaceae \\
\hline Erva-de-santa-luzia & Chamaesyce hirta & Euphorbiaceae \\
\hline Amedoim-bravo & Euphorbia heterophylla & Euphorbiaceae \\
\hline Nabiça & Raphanus raphanistrum & Cruciferae \\
\hline Mastruço & Coronopus didymus & Cruciferae \\
\hline Trevo (azedinha) & Oxalis corniculata & Oxalidaceae \\
\hline Trapoeraba & Commelina benghalensis & Commeliaceae \\
\hline Guanxuma & Sida rhombifolia & Malvaceae \\
\hline Aipo-bravo & Apium leptophyllum & Umbeliferae \\
\hline Orelha-de-urso & Stachys arvensis & Labiatae \\
\hline Erva-de-passarinho & Stellaria media & Caryophyllaceae \\
\hline
\end{tabular}




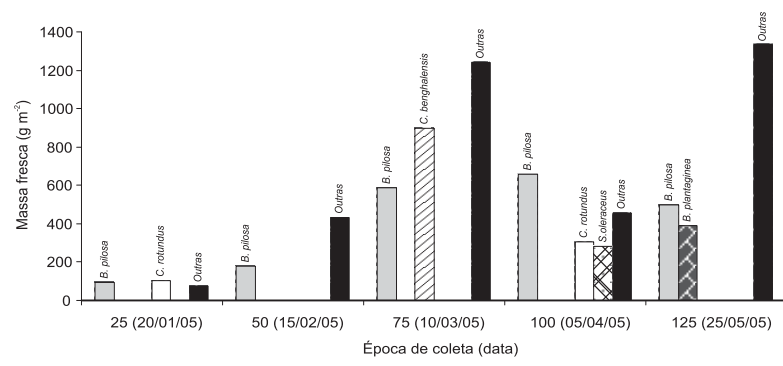

Figura 3 - Massa fresca de plantas daninhas em competição com a cultura de mandioca, coletadas aos $0,25,50,75,100$ e 125 dias após o plantio da cultura. Viçosa-MG, 2006.

Bidens pilosa (179 $\left.\mathrm{g} \mathrm{m}^{-2}\right)$; aos 75 dias, de Commelina benghalensis ( $895 \mathrm{~g} \mathrm{~m}^{2}$ ); e aos 100 e 125 dias, novamente de Bidens pilosa (655 e $500 \mathrm{~g} \mathrm{~m}^{-2}$, respectivamente) (Figura 3).

A espécie Bidens pilosa novamente apresentou as maiores produções de massa fresca nas épocas de coleta aos 150, 175, 200 e 325 dias, com 265, 324, 211 e $11 \mathrm{~g} \mathrm{~m}^{-2}$, respectivamente (Figura 4). Os diferentes niveis de dormência das sementes do picão-preto e a alta disponibilidade de sementes desta espécie no solo, associados às condições ótimas de temperatura ambiente - segundo Chivinge (1996), a temperatura entre 20 e $35^{\circ} \mathrm{C}$ favorece a germinação de sementes de picão-preto -, podem explicar a dominância desta espécie na maior parte do ano. Dentre os recursos passíveis de competição entre culturas e plantas daninhas, a extração e acúmulo de nutrientes parece ser a principal característica quando se estuda toda a comunidade infestante em competição com culturas de ciclo intermediário, como é o caso da mandioca. A capacidade diferencial das espécies vegetais infestantes quanto à extração de nutrientes no solo pode ser atribuída ao volume de solo explorado pelo sistema radicular, à fertilidade do solo e à capacidade de acúmulo de nutrientes pelas espécies. Para Ronchi et al. (2001), Bidens pilosa é capaz de acumular teores relativamente altos de nitrogênio, fósforo e de micronutrientes. Para Klein \& Felipe (1998), sementes de picão-preto germinam também na ausência da luz. Esses fatos foram verificados durante as épocas de coleta, contribuindo para a maior infestação desta espécie (Figuras 3 e 4). Outra característica importante de plantas de Bidens pilosa é a alta capacidade que esta espécie tem de extrair água do solo (três vezes

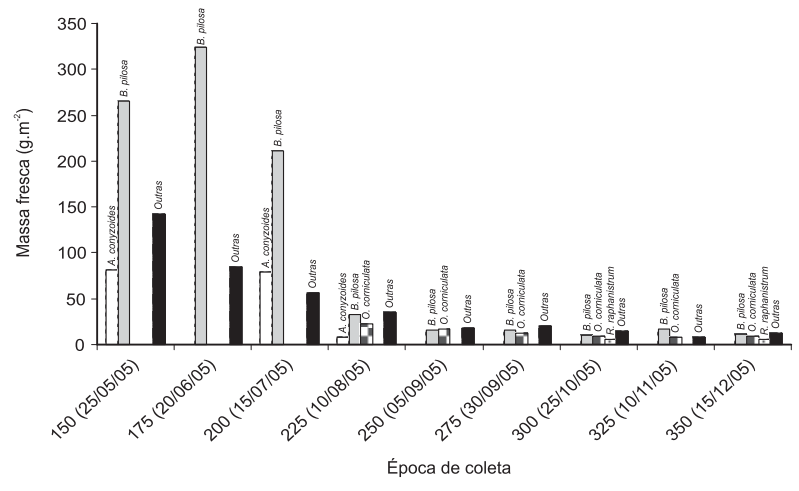

Figura 4 - Massa fresca de plantas daninhas em competição com a cultura de mandioca, coletadas aos 150, 175, 200, $225,250,275,300,325$ e 350 dias após o plantio da cultura. Viçosa-MG, 2006.

maior que a capacidade da soja ou feijão) (Procópio et al., 2004).

Quanto a Oxadis corniculata, observou-se que esta apresentou elevada produção de massa fresca a partir de 200 dias após o plantio (Figura 4). Trata-se de uma espécie medianamente freqüente em todo o território brasileiro, exceto na Amazônia, sendo tolerante ao sombreamento (Lorenzi, 2000). Esse fato é atribuído à alta infestação dessa espécie após completa cobertura do solo pela cultura. A partir dos 150 dias, as espécies pertencentes à classe das monocotiledôneas diminuíram consideravelmente a produção de massa verde.

Avaliando a produtividade da cultura, observou-se decréscimo na produção de raízes no primeiro experimento, quando os períodos de convivência das plantas daninhas com a cultura foram iguais e superiores a 50 dias entre o plantio e a capina. As perdas no rendimento foram superiores a $90 \%$ quando a primeira capina foi realizada após 100 dias de convivência da cultura com as plantas daninhas (Tabela 5). O fato de o índice de colheita se manter inalterado na maioria dos tratamentos indica que a diminuição da parte aérea está intimamente ligada ao decréscimo de rendimento das raízes, ou seja, as plantas daninhas influenciam o crescimento geral da cultura da mandioca.

A produção de raízes ficou abaixo dos $3,0 \mathrm{~kg} \mathrm{ha}^{-1}$, inviabilizando a determinação de massa e do teor de amido quando a competição da cultura com as plantas daninhas foi realizada somente aos 100 DAP (Figura 5). 
Tabela 5 - Médias de produtividade de raízes (PROD), peso da parte aérea (PPA), índice de colheita (IC), teor de amido (TA) e matéria seca de raízes (MSR) do cultivar de mandioca, referentes ao experimento 1. Viçosa-MG, 2006

\begin{tabular}{|c|c|c|c|c|c|}
\hline Tratamento & $\begin{array}{c}\text { PROD } \\
\left(\mathrm{kg} \mathrm{ha}^{-1}\right)\end{array}$ & $\begin{array}{c}\text { PPA } \\
\left(\mathrm{kg} \mathrm{ha}^{-1}\right)\end{array}$ & $\begin{array}{l}\text { IC } \\
(\%)\end{array}$ & $\begin{array}{l}\text { TA } \\
(\%)\end{array}$ & $\begin{array}{c}\text { MSR } \\
(\%)\end{array}$ \\
\hline Testemunha $1^{\underline{1} /}$ & $21,752 \mathrm{~A}^{*}$ & $29,187 \mathrm{~A}$ & $42,73 \mathrm{~A}$ & $28,88 \mathrm{~A}$ & $33,53 \mathrm{~A}$ \\
\hline $\mathrm{CPD}^{3 /}$ após $25 \mathrm{DAP}^{4 /}$ & $22,775 \mathrm{~A}$ & $30,344 \mathrm{~A}$ & $43,58 \mathrm{~A}$ & $28,33 \mathrm{AB}$ & $32,98 \mathrm{AB}$ \\
\hline CPD após 50 DAP & $12,845 \mathrm{~B}$ & $23,906 \mathrm{AB}$ & $35,70 \mathrm{~A}$ & $27,08 \mathrm{AB}$ & $31,72 \mathrm{AB}$ \\
\hline CPD após 75 DAP & $13,155 \mathrm{~B}$ & $21,844 \mathrm{AB}$ & $41,15 \mathrm{~A}$ & $26,60 \mathrm{~B}$ & $30,69 \mathrm{~B}$ \\
\hline CPD após $100 \mathrm{DAP}$ & $1,725 \mathrm{C}$ & $13,281 \mathrm{BC}$ & $9,25 \mathrm{BC}$ & $0,0 \mathrm{C}$ & $0,0 \mathrm{C}$ \\
\hline CPD após 125 DAP & $1,675 \mathrm{C}$ & $11,961 \mathrm{BC}$ & $16,58 \mathrm{~B}$ & $0,0 \mathrm{C}$ & $0,0 \mathrm{C}$ \\
\hline Testemunha $2^{2 /}$ & $0,0 \mathrm{C}$ & $4,840 \mathrm{C}$ & $0,0 \mathrm{C}$ & $0,0 \mathrm{C}$ & $0,0 \mathrm{C}$ \\
\hline CV $(\%)$ & 15,42 & 27,27 & 16,35 & 5,95 & 5,70 \\
\hline
\end{tabular}

* Médias seguidas de mesma letra na coluna não diferem significativamente a $5 \%$ de probabilidade pelo teste de Tukey. ${ }^{1 /} \mathrm{e}$ ㄴ/ Cultivo livre e com plantas daninhas durante todo o ciclo, respectivamente; $3 /$ convivência com plantas daninhas; ${ }^{4 /}$ dias após o plantio.

As maiores produtividades de raízes foram observadas na testemunha livre de competição e no tratamento onde a convivência da cultura com as plantas daninhas apenas ocorreu até 25 dias após o plantio. Resultados semelhantes aos observados neste trabalho foram também verificados por Carvalho et al. (2004). Esses autores relatam que a cultura da mandioca, no litoral baiano, pode conviver com as plantas infestantes por um período de 20 a 30 dias após a brotação, aproximadamente 35 a 45 dias depois do plantio, sem prejuízo significativo na produção de raízes.

A capina realizada após 50 dias de convivência entre cultura e plantas daninhas ocasionou perda de $56 \%$ na produtividade da mandioca (Tabela 5). Para Alcântara et al. (1982), ao se iniciarem as mondas aos 60 dias após o brotamento, há redução no rendimento de raízes e parte aérea, o que é condizente com os dados obtidos por Carvalho et al. (1990).

De acordo com Pacheco et al. (1974), a competição de plantas daninhas com a mandioca nos primeiros três meses reduz sensivelmente o rendimento da cultura, concluindo-se que, nesse período, há maior concorrência pelos fatores de produção. Alcântara et al. (1982) relatam que a cultura da mandioca é mais sensível à competição quando o período de convivência é superior a 60 dias após o plantio. Pinho et al. (1980) constataram que capinas realizadas até 90 dias após o plantio aumentam consideravelmente a produção de ramas e raízes de mandioca.
De modo geral, os resultados verificados neste trabalho (Tabela 5) - em que menores produtividades foram obtidas nos tratamentos com as capinas realizadas após 100 dias de convivência e na testemunha sem capina não houve produção de raízes tuberosas - estão de acordo com os dados da literatura, como observado por Peressin (1997). Segundo este autor, em diversos trabalhos desenvolvidos para a Seção de Raízes e Tubérculos do Instituto Agronômico de Campinas (IAC) do Estado de São Paulo, a convivência das plantas daninhas com a cultura da mandioca durante todo o primeiro ciclo da cultura levou à redução da produção da ordem de até $98 \%$ sobre o peso das raízes. A característica índice de colheita foi alterada a partir da convivência das plantas daninhas com a cultura após 100 DAP.

No experimento 2, ficou evidenciado o efeito nocivo da competição das plantas daninhas sobre as características avaliadas na cultura. Somente plantas daninhas que emergirem a partir de 75 dias após o plantio da cultura não mais irão ocasionar interferência negativa sobre a produtividade de raizes e o peso de parte aérea da cultura (Tabela 6). Observou-se que o tratamento mantido livre de plantas daninhas durante todo o ciclo da cultura foi o que apresentou o maior peso da parte aérea, com $44.875 \mathrm{~kg} \mathrm{ha}^{-1}$, porém não diferiu dos tratamentos LPD até 75 DAP (40.593 $\left.\mathrm{kg} \mathrm{ha}^{-1}\right)$, até 100 DAP $\left(40.500 \mathrm{~kg}\right.$ ha $\left.{ }^{1}\right)$ e até 125 DAP $\left(38.969 \mathrm{~kg} \mathrm{ha}^{-1}\right)$. A produção de parte aérea é de grande importância para a mandiocultura, 
para produção de raízes tuberosas, material de propagação, produção de forragem para alimentação animal, além de ser a parte da planta responsável pela absorção de luz e fornecimento de fotoassimilados às raízes.

As outras características avaliadas - indice de colheita, teor de amido e matéria seca de raízes - apresentaram resultados semelhantes, ou seja, à exceção da testemunha sem capina, os outros tratamentos não diferiram entre si (Tabela 6). De acordo com Conceição (1986), um bom índice de colheita deve ser no mínimo de 60\%; desse modo, os tratamentos não apresentaram bom indice de colheita. Esse fato pode significar menor eficiência das plantas de mandioca no acúmulo de amido. Contudo, deve-se levar em consideração que índice de colheita ideal pode não significar boa produtividade. A exemplo do observado neste experimento, considerando-se a baixa produção de massa fresca da parte aérea, a relação entre esta e as raízes produzirá maior índice de colheita, inviabilizando sua consideração como fator de produtividade.

Todavia, analisando o experimento como um todo, verificou-se que não é necessária a manutenção do mandiocal sempre no limpo durante todo o ciclo. Essa prática não é recomendável, pois, com a manutenção do solo totalmente livre de plantas daninhas, há aumento da erosão e também maior custo de produção. Além disso, a presença das plantas daninhas em período em que não mais ocorre competição pelos fatores do crescimento é fundamental para reciclagem de nutrientes e manutenção de camada protetora, devendo a capina ser realizada apenas quando necessária. Neste trabalho, ficou evidente, para as condições estudadas, que a primeira capina deve ser realizada próximo aos 25 DAP e as últimas, próximo aos $75 \mathrm{DAP}$.

Com base nos resultados das Tabelas 5 e 6, procurou-se estabelecer relação entre os dois experimentos com a finalidade de determinar os períodos considerados como anterior à interferência (PAI), posterior à interferência (PPI) e crítico de interferência (PCI) - períodos estes estabelecidos por Pitelli \& Durigan (1984). Admitindo-se que os aspectos econômicos, incluindo o custo de controle das plantas daninhas e o valor comercial das raízes por ocasião dos tratos culturais, interferem no custo total de produção, eles devem ser utilizados como critério para se determinar o período aceitável de interferência das plantas daninhas antes da tomada de decisão para o controle. Vidal et al. (2005) estabeleceram o período anterior ao dano no rendimento econômico (PADRE). Segundo os autores, esse período diminui com o incremento no preço da cultura e/ou com a redução do custo de controle e com o aumento do potencial produtivo da cultura, indicando que, nessas condições, o controle precoce das plantas infestantes é economicamente justificável. Neste trabalho, admitindo-se perda de $10 \%$ para estabelecimento do período no qual

Tabela 6 - Médias de produtividade de raízes (PROD), peso da parte aérea (PPA), índice de colheita (IC), teor de amido (TA) e matéria seca de raízes (MSR) do cultivar de mandioca, referentes ao experimento 2. Viçosa-MG, 2006

\begin{tabular}{|c|c|c|c|c|c|}
\hline Tratamento & $\begin{array}{l}\text { PROD } \\
\left(\mathrm{kg} \mathrm{ha}^{-1}\right)\end{array}$ & $\begin{array}{c}\text { PPA } \\
\left(\mathrm{kg} \mathrm{ha}^{-1}\right)\end{array}$ & $\begin{array}{l}\text { IC } \\
(\%)\end{array}$ & $\begin{array}{l}\text { TA } \\
(\%)\end{array}$ & $\begin{array}{l}\text { MS } \\
(\%)\end{array}$ \\
\hline Testemunha $1^{1 /}$ & $17,594 \mathrm{~A}^{*}$ & $44,875 \mathrm{~A}$ & $28,00 \mathrm{~A}$ & $28,88 \mathrm{~A}$ & $33,43 \mathrm{~A}$ \\
\hline Testemunha $2^{2 /}$ & $0,0 \mathrm{C}$ & $8,563 \mathrm{D}$ & $0,0 \mathrm{~B}$ & $0,0 \mathrm{~B}$ & $0,0 \mathrm{~B}$ \\
\hline $\mathrm{LPD}^{3 /}$ até $25 \mathrm{DAP}^{4 /}$ & $3,844 \mathrm{C}$ & $21,531 \mathrm{CD}$ & $17,03 \mathrm{~A}$ & $20,45 \mathrm{~A}$ & $33,94 \mathrm{~A}$ \\
\hline LPD até $50 \mathrm{DAP}$ & $12,312 \mathrm{~B}$ & $27,250 \mathrm{BC}$ & $32,75 \mathrm{~A}$ & $28,90 \mathrm{~A}$ & $33,55 \mathrm{~A}$ \\
\hline LPD até 75 DAP & $16,812 \mathrm{AB}$ & $40,593 \mathrm{AB}$ & $29,09 \mathrm{~A}$ & $29,62 \mathrm{~A}$ & $34,27 \mathrm{~A}$ \\
\hline LPD até 100 DAP & $19,156 \mathrm{~A}$ & $40,500 \mathrm{AB}$ & $32,64 \mathrm{~A}$ & $29,65 \mathrm{~A}$ & $34,30 \mathrm{~A}$ \\
\hline LPD até 125 DAP & $17,594 \mathrm{~A}$ & $38,969 \mathrm{AB}$ & $32,88 \mathrm{~A}$ & $29,03 \mathrm{~A}$ & $33,68 \mathrm{~A}$ \\
\hline $\mathrm{CV}(\%)$ & 17,50 & 19,93 & 32,69 & 21,98 & 22,01 \\
\hline
\end{tabular}

${ }^{*}$ Médias seguidas de mesma letra na coluna não diferem significativamente a $5 \%$ de probabilidade pelo teste de Tukey. ${ }^{1 / \mathrm{e}} 2 /$ Cultivo livre e com planta daninha durante todo o ciclo, respectivamente; ${ }^{3 /}$ livre de plantas daninhas; ${ }^{4 /}$ dias após o plantio. 
a cultura deveria permanecer sem a interferência das plantas daninhas (PCI), o controle deverá ser efetuado entre 25 e 50 dias de convivência (Tabela 5). No entanto, é importante lembrar que períodos de convivência muito longos após o plantio (50 dias) podem comprometer mais de $40 \%$ da produtividade. Da mesma for$\mathrm{ma}$, as plantas daninhas que emergirem e se desenvolverem até 50 dias após o plantio também comprometem a cultura.

Os resultados obtidos permitiram concluir que, na área experimental, foram encontradas 37 espécies, distribuídas em 14 famílias botânicas, e as que mais predominaram foram: Bidens pilosa, Raphanus raphanistrum, Cyperus rotundus, Commelina benghalensis, Ageratum conyzoides, Ipomoea purpurea e Brachiaria plantaginea. A espécie Bidens pilosa predominou em quase todas as épocas de coleta, e os periodos de convivência com as plantas daninhas não interferiram nos índices de colheita, teor de amido e matéria seca das raízes de mandioca. O período anterior à interferência (PAI) foi próximo aos 25 dias após o plantio; o período crítico de prevenção à interferência (PCPI) encontra-se no intervalo de 25 a 75 dias; e o período posterior à interferência (PPI) foi a partir dos 75 dias após o plantio.

\section{LITERATURA CITADA}

ALBUQUERQUE, M.; CARDOSO, E. M. R. Utilização da mandioca na Amazônia. Belém: Embrapa-CPATU, 1983. (Documento, 25)

ALCÂNTARA, E. N.; CARVALHO, J. E. B.; LIMA, P. C Determinação do período crítico de competição das plantas daninhas com a cultura da mandioca (Manihot esculenta Crantz). In: EPAMIG. Projeto mandioca; relatório 76/79. Belo Horizonte: 1982.

AZEVÊDO, C. L. L. et al. Levantamento de plantas daninhas na cultura da mandioca, em um ecossistema semiárido do Estado da Bahia. Magistra, v. 12, n. 1/2, 2000 Disponível em: $<$ http://www.magistra.ufba.br/publica/ magist>. Acesso em: 15 de março de 2006.

CARVALHO, J. E. B. Plantas daninhas e seu controle. In MATTOS, P. L. P.; GOMES, J. C. (Coords.). O cultivo da mandioca. Cruz das Almas: Embrapa Mandioca e Fruticultura, 2000. p. $42-52$

CARVALHO, J. E. B.; ARAÚJO, A. M. A.; AZEVEDO, C. L. L. Período de controle de plantas infestantes na cultura da mandioca no Estado da Bahia. Cruz das Almas 2004. 7 p.(Comunicado Técnico, 109).

Planta Daninha, Viçosa-MG, v. 26, n. 2, p. 279-289, 2008
CARVALHO, J. E. B. et al. Período crítico de competição das plantas daninhas com a cultura da mandioca em três ecossistemas do Nordeste brasileiro. R. Bras. Mandioca, v. 9 , p. $29-40,1990$

COMISSÃO DE FERTILIDADE DO SOLO DO ESTADO DE MINAS GERAIS - CFSEMG. Recomendações para uso de corretivos e fertilizantes em Minas Gerais: 5’ aproximação. Viçosa, MG: 1999. 360 p.

CHIVINGE, O. Studies on the germination and seedling emergence of Bidens pilosa and its response to fertilizer application. Trans. Zimb. Sci. Assoc., v. 70, p. 1-5, 1996.

CONCEIÇÃO, A. J. A mandioca. São Paulo: Nobel, 1986 $382 \mathrm{p}$

FAO. Maiores produtores mundiais de mandioca. Disponível em: <http://apps.fao.org/egibin/nphdb.p12006> Acesso em: 8 de jun. de 2006.

GROSSMANN, J.; FREITAS, A. C. Determinação do teor de matéria seca pelo peso específico em raízes de mandioca. R. Agron., v. 160/162, n. 4, p. 75-80, 1950.

INSTITUTO BRASILEIRO DE GEOGRAFIA E ESTATÍSTICA - IBGE. Levantamento Sistemático da Produção Agrícola - LSPA. Rio de Janeiro: 2006.

IITA. Cassava productivity in the lowland and midaltitude agroecologies of sub-saharan Africa. Disponível em: $<$ http://www.iita.org/research $>$. Acesso em: 22 de ago. de 2005.

JAKELAITIS, A. et al. Dinâmica populacional de plantas daninhas sob diferentes sistemas de manejo nas culturas de milho e feijão. Planta Daninha, v. 21, n. 1, p. 71-79, 2003

KLEIN, A.; FELIPE, G. M. Efeitos da luz na germinação de sementes de ervas invasoras. Pesq. Agropec. Bras., v. 26, n. 7, p. 955-966, 1998.

LORENZI, H. Plantas daninhas do Brasil: terrestres, aquáticas, parasitas e tóxicas. 3.ed. Nova Odessa: Instituto Plantarum, 2000

MATTOS, P. L. P.; CARDOSO, E. M. R. Plantas daninhas. Disponível em: $<$ http://

sistemasdeproduçao.cnptia.embrapa.br>. Acesso em: 22 de ago. de. 2005

PACHECO, C.; CHAVARRIA, P. L.; MATA, R. H. Herbicidas em pré-emergência en el cultivo de la yuca (Manihot esculenta Crantz). Costa Rica: Estación Experimental Fábio Banchit, 1974. 12 p. (Comunicado Técnico, 1). 
PAIXÃO, L. M. B. V. S.; CARVALHO, J. E. B.; COSTA, J. J. A. Efeito de densidades populacionais da tiririca (Cyperus rotundus L.) sobre o desenvolvimento da mandioca (Manihot esculenta Crantz). R. Bras. Mandioca, v. 14, n. 1/2, p. 52$61,1995$.

PERESSIN, V. A. Mato-interferência na cultura da mandioca (Manihot esculenta Crantz). 1997. 132 f. Tese (Doutorado em Agronomia) - Universidade Estadual Paulista, Jaboticabal, 1997.

PINHO, J. L. N. et al. Controle de plantas daninhas na cultura da mandioca (Manihot esculenta Crantz), no Ceará. In: EPACE. Relatório anual de pesquisa da EPACE. Fortaleza: 1980. p. 53-81.

PITELLI, R. A. Interferência de plantas daninhas em cultivos agrícolas. Inf. Agropec., v. 11, p. 16-26, 1985.

PITELLI, R. A.; DURIGAN, J. C. Terminologia para períodos de convivência de plantas daninhas em culturas anuais e bianuais. In: CONGRESSO BRASILEIRO DE HERBICIDAS E PLANTAS DANINHAS, 15., 1984, Belo Horizonte. Resumos... Piracicaba: Sociedade Brasileira da Ciência das Plantas Daninhas, 1984. p. 37.
PROCÓPIO, S. O. et al. Ponto de murcha permanente de soja, feijão e plantas daninhas. Planta Daninha, v. 22, n. 1, p. 35-41, 2004.

RIBEIRO Jr., J. I. Análises estatísticas no SAEG - guia prático. Viçosa, MG: Universidade Federal de Viçosa, 2004.

RONCHI, C. P.; SILVA, A. A.; FERREIRA, L. R. Manejo de plantas daninhas em lavouras de café. Viçosa, MG: Suprema, 2001. 94 p.

SILVA, A. A. et al. Biologia de plantas daninhas. In: SILVA, A. A.; SILVA, J. F. (Eds.) Tópicos em manejo de plantas daninhas. Viçosa, MG: Universidade Federal de Viçosa, 2007. p. $17-62$

VIDAL, R. A.; FLECK, N. G.; MEROTTO JR., A. Período anterior ao dano no rendimento econômico (PADRE): nova abordagem sobre os períodos de interferência entre plantas daninhas e cultivadas. Planta Daninha, v. 23, n. 3, p. $387-$ 396, 2005.

VIEGAS, A. P. Estudos sobre a mandioca. Campinas: IAC/ BRASCAN NORDESTE, 1976. 214 p. 